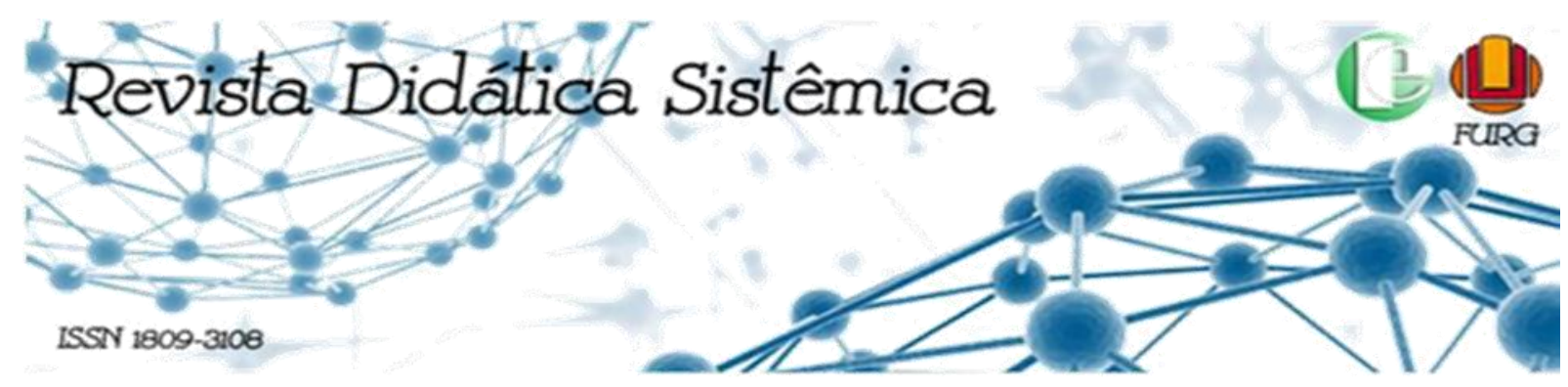

\title{
PRÁTICAS AVALIATIVAS DE PROFESSORES DE EDUCAÇÃO FÍSICA DE UMA ESCOLA DA REDE PÚBLICA DE ENSINO DE CANGUÇU/RS
}

\author{
Angélica Vilela Lessa* \\ Luiz Fernando Camargo Veronez ${ }^{* *}$ \\ Luiz Carlos Rigo ${ }^{* * *}$
}

\begin{abstract}
RESUMO
O objetivo deste estudo é diagnosticar quais são as práticas avaliativas dos professores de educação física de uma escola de Canguçu/RS e como elas são construídas ao longo de suas trajetórias. Para tanto, foi realizada uma pesquisa qualitativa, através de um estudo de caso (GIL, 2007). Os resultados indicam que as práticas de avaliação mais utilizadas pelos professores entrevistados foram a observação do aluno em aula e a aplicação de provas e trabalhos teóricos. A pesquisa concluiu, também, que, apesar dos desafios e das dificuldades encontradas pelos professores, há uma busca de sua parte no sentido de qualificar sua prática pedagógica.
\end{abstract}

Palavras-chave: Práticas Avaliativas. Educação Física. Trajetória Docente.

\section{EVALUATION PRACTICES OF TEACHERS OF PHYSICAL EDUCATION OF SCHOOLS OF THE PUBLIC EDUCATION NETWORK OF CANGUÇU/RS}

\begin{abstract}
The objective of this study was to diagnose what are the evaluative practices of physical education teachers and how they are constructed along their trajectories. For that, a qualitative research was carried out, through a case study (GIL, 2007). The results indicate that the evaluation practices most used by the interviewed teachers were the observation of the student in class and the application of tests and theoretical works. The research also concluded that despite the challenges and difficulties encountered by teachers, there is a search for part of them in order to qualify their pedagogical practice.
\end{abstract}

Keywords: Evaluative practices. Physical Education. Trajectory Lecturer.

\section{PRÁCTICAS EVALUADAS DE PROFESORES DE EDUCACIÓN FÍSICA DE ESCUELAS DE LA RED PÚBLICA DE ENSEÑANZA DE CANGUÇU / RS}

\section{RESUMEN}

El objetivo de este estudio fue diagnosticar cuáles son las prácticas de evaluación de los profesores de educación física y cómo se construyen a lo largo de sus trayectorias. Para ello, se realizo

\footnotetext{
* Mestre em Educação Física pela Universidade Federal de Pelotas - UFPel

** Professor Doutor da Universidade Federal de Pelotas - UFPel

**** Professor da Universidade Federal de Pelotas - UFPel. Pós Doutorado no Programa Interdisciplinar em Ciências Humanas (PPGICH) da Universidade Federal de Santa Catarina - UFSC
} 
una investigación cualitativa, a través de un estudio de caso (GIL, 2007). Los resultados indican que las prácticas de evaluación más utilizadas por los profesores entrevistados fueron la observación del alumno en clase y la aplicación de pruebas y trabajos teóricos. La investigación concluyó también que a pesar de los desafíos y de las dificultades económicas por los profesores hay una búsqueda de parte de los mismos en el sentido de calificar su práctica pedagógica.

Palabras clave: Prácticas evaluativas. Educación Física. Maestro trayectoria.

\section{INTRODUÇÃO}

Segundo Ferreira (1986), o conceito de avaliação significa determinar a valia ou o valor de; calcular; apreciar ou estimar o merecimento. Trata-se, portanto, de um processo, a parâmetros pré-estabelecidos, escolhidos e confrontados, com o objetivo de qualificar, ou quantificar, determinado procedimento que se deseja definir. Estas qualidades e quantidades referenciais, como o próprio nome nos propõe, são utilizadas para que possamos entender em qual grau está aquela qualidade/quantidade que se pretende qualificar/quantificar.

Para Libâneo (1994), a prática da avaliação nas escolas têm sido alvo de críticas, principalmente por se reduzir à função de controle e por priorizar procedimentos de avaliações quantitativas. Apesar de existir, praticamente, um consenso entre os educadores sobre a importância do ato de avaliar o processo de ensino e de aprendizagem, muitos professores encontram dificuldade em utilizar a avaliação como um instrumento pedagógico que seja capaz de ajudar a qualificar sua prática docente.

Um dos questionamentos que se faz sobre o processo avaliativo no âmbito escolar refere-se ao exagerado uso de provas como o único ou o principal instrumento de avaliação (FERNANDES E GREENVILE, 2007). Desse modo, faz-se necessário atentar para o ato de avaliar como uma habilidade (FEITOSA E NASCIMENTO, 2006). Dessa forma, os professores precisam atentar para saber o que, como, porque e para que avaliar. Assim, é preciso avaliar, com sabedoria, para possibilitar uma avaliação coesa e coerente com a prática pedagógica utilizada.

Tardif (2000) afirma que os professores constroem-se a partir de saberes que adquirem em suas trajetórias profissionais e, principalmente, como utilizam estes saberes, especialmente para construir estratégias metodológicas e jeitos de avaliar. Assim, a prática avaliativa utilizada pelo professor será um dos fatores constituintes do processo educativo, que dará subsídio para a formação do educando. A prática pedagógica produz, 
por conseguinte, saberes determinantes para o seu exercício pedagógico. Neste sentido, a maioria dos professores são conhecedores da importância da avaliação na construção da formação dos alunos e, se sentem habilidosos no seu ato de avaliar. No entanto, é necessário um repensar constante, tanto das práticas educativas como, especificamente, das práticas avaliativas. (BERMUDES, 2010).

Partindo dessas premissas, optamos por investigar as estratégias avaliativas que constituem as práticas educativas de alguns professores de Educação Física de uma escola pública da rede estadual de Canguçu/RS. Escolhemos esta escola como objeto de pesquisa por se tratar da instituição com maior número de alunos matriculados do município, atendendo ao Ensino Fundamental, Ensino Médio e Educação de Jovens e Adultos (EJA).

Mais especificamente, procuramos: a) Analisar a trajetória das práticas avaliativas, a partir dos saberes dos professores de Educação Física, de uma escola da rede pública de Canguçu - RS, notadamente nos anos finais do ensino fundamental; b) Constatar os saberes utilizados nas práticas avaliativas dos professores entrevistados; c) Identificar a construção dos saberes ligados ou não a algum significado/sentimento; d) Detectar os principais instrumentos e registros avaliativos utilizados nas práticas avaliativas.

\section{CAMINHOS METODOLÓGICOS}

Este estudo caracteriza-se por uma pesquisa qualitativa de caráter descritivo que, segundo Gil (2007), tem como objetivo primordial a descrição das características de determinada população ou fenômeno. Em consonância com o autor, Lakatos et al (1986) afirmam que a interpretação dos fenômenos e a atribuição de significados são básicas no processo de pesquisa qualitativa. $\mathrm{O}$ ambiente natural é a fonte direta para coleta de dados e o pesquisador é o instrumento-chave. Os pesquisadores tendem a analisar seus dados indutivamente e o processo e seu significado são os focos principais de abordagem.

A pesquisa realizada apresenta algumas características, que, segundo as classificações apresentadas por Gil (2007), as aproximam de um tipo pesquisa que o autor denomina de estudo de casos múltiplos. Este tipo de pesquisa consiste em uma modalidade de estudo que procura fazer uma análise ampla, mas também bastante detalhada do objeto, ou fenômeno pesquisado.

O estudo contou com a participação de 4 professores de Educação Física, atuantes nos anos finais do ensino fundamental, lotados em uma escola da rede estadual de ensino 
da cidade de Canguçu/RS. A instituição escolar e os respectivos professores, foram informados dos objetivos deste estudo. Houve anuência da instituição escolar, assim como assinatura do termo de consentimento pelos docentes envolvidos.

Para a coleta de dados, utilizamos uma entrevista semiestruturada (TRIVIÑOS, 1987), composta por um roteiro de perguntas, que foi elaborado pelos autores desse estudo. O roteiro priorizou questões relacionadas à formação e ao desenvolvimento do trabalho do professor de Educação Física, mais especificamente questões referentes às suas práticas avaliativas. O primeiro contato foi realizado com a Coordenadoria Regional de Educação ( $\left.5^{\circ} \mathrm{CRE}\right)$ para autorização da pesquisa na escola da cidade. Após a concessão desta, foi feito um contato com a escola e com cada um dos professores envolvidos, para organizar o agendamento das entrevistas.

\section{ANÁLISE E DISCUSSÃO DOS RESULTADOS}

Segundo Patton (1980 citado por GIL, 1999), a análise de dados qualitativos é um processo criativo, que exige rigor intelectual e dedicação. $O$ autor adverte que não existe uma forma melhor ou mais correta. O que se exige são sistematização e coerência do esquema adotado com o que pretende o estudo. Desse modo, utilizamos, nesta pesquisa, alguns princípios de análise, oriundos do método da análise de conteúdo (BARDIN, 1990), principalmente no que se refere à análise de hipóteses e/ou questões. Ou seja, através da análise de conteúdo, podemos encontrar respostas para as questões formuladas e, também, podemos confirmar, ou não, as afirmações estabelecidas antes do trabalho de investigação. A outra função diz respeito à interpretação dos sentidos dos conteúdos manifestados. (MINAYO, 2001).

Participaram deste estudo 4 professores de Educação Física, 2 do sexo feminino e 2 do masculino (Tabela 01). Para propiciar uma visualização acessível e uma rápida identificação, utilizamos a nomenclatura professor $(\mathrm{P})$, nomeando de forma genérica os professores que participaram do estudo, em um número correspondente à ordem de cada uma das entrevistas realizadas. (P1; P2; P3; P4). 
Tabela 01 - Caracterização da Amostra

\begin{tabular}{|c|c|c|c|c|c|c|c|}
\hline Professores & Sexo & Idade & $\begin{array}{c}\text { Instituição } \\
\text { Formação } \\
\text { Inicial }\end{array}$ & $\begin{array}{c}\text { Pós- } \\
\text { Graduação }\end{array}$ & $\begin{array}{c}\mathbf{N}^{\circ} \text { de } \\
\text { Escolas } \\
\text { Onde } \\
\text { Atua }\end{array}$ & $\begin{array}{c}\text { Carga } \\
\text { Horária } \\
\text { Atual }\end{array}$ & $\begin{array}{c}\text { Tempo } \\
\text { de } \\
\text { Serviço }\end{array}$ \\
\hline $\begin{array}{ll}\text { P.1 } \\
\end{array}$ & Fem. & $\begin{array}{c}27 \\
\text { anos }\end{array}$ & UFPel & Sim & 2 & 40 & 2 anos \\
\hline P. 2 & Fem. & $\begin{array}{c}25 \\
\text { anos }\end{array}$ & Anhanguera & Sim & 1 & 40 & 3 anos \\
\hline P.3 & Masc. & $\begin{array}{c}37 \\
\text { anos }\end{array}$ & UFPel & Sim & 2 & 40 & 10 anos \\
\hline P.4 & Masc. & $\begin{array}{c}44 \\
\text { anos }\end{array}$ & Atlântico Sul & Sim & 2 & 40 & 20 anos \\
\hline
\end{tabular}

Fonte: autores da pesquisa.

A partir dos dados, podemos perceber que os entrevistados possuem uma formação/aperfeiçoamento e também experiência profissional, que lhes permite compor, avaliar e refletir sobre sua prática (TARDIF, 2002). Libâneo (1994, p. 225) ressalta que “a ação docente vai ganhando eficácia na medida em que o professor vai acumulando e enriquecendo experiências ao lidar com as situações concretas de ensino”, proporcionando uma vasta produção de saberes durante sua trajetória de educador.

Uma das perguntas da nossa entrevista referia-se à importância e ao papel da avaliação na Educação Física Escolar, na opinião dos entrevistados. Sobre essa questão, selecionamos as respostas dadas pelos professores P1 e P3. Ambos salientaram a importância da avaliação e destacaram que:

Acredito sim na avaliação, porque é importante e necessária, através dela analisamos o desenvolvimento de cada aluno e também repensamos nossa prática, de forma a atingirmos nossos objetivos. (P.1).

Acho fundamental. Porque valoriza o trabalho desenvolvido em cada trimestre, e faz com que o aluno encare a nossa disciplina não apenas como o momento de jogar ou brincar e sim de adquirir conhecimentos que vão além do esportivo através de nossos conteúdos. Como os relacionados à saúde, por exemplo. (P.3).

Nota-se, na narrativa dos entrevistados, que os mesmos se ancoram no método da avaliação diagnóstica para realizar suas avaliações. Segundo Luckesi (2000), trata-se 
de uma proposta avaliativa que prioriza a compreensão do estágio de aprendizagem em que o aluno se encontra, para, a partir dela, tomar decisões que possam avançar no processo de aprendizagem. Nesse caso, avaliar se configura como ato de diagnosticar uma experiência, com a intenção de reorientá-la para qualificar a prática pedagógica.

Percebe-se, na fala do P.3, uma preocupação com a valorização da educação física enquanto disciplina em que se salienta seus conteúdos e objetivos e ressalta a importância da Educação Física para a saúde do estudante na escola. Essa preocupação, enfatizada pelo entrevistado P.3, faz parte das indicações contidas nos próprios PCN's (BRASIL, 1997), em que também se faz referência à importância de temas, como a saúde no contexto da vida escolar.

[...] A incidência cada vez maior de adolescentes e jovens obesos, com dificuldades oriundas da falta de movimento, com possibilidades de acidentes cardiovasculares e com oportunidades reduzidas de movimento, leva-nos a pensar na retomada da vertente voltada à Aptidão Física e Saúde (BRASIL, 1997).

Já segundo a Base Nacional Comum Curricular - BNCC (BRASIL, 2017), a Educação Física, parte integrante da área das Linguagens, tem como propósito central contribuir para a constituição da subjetividade humana, conforme os próprios conteúdos dos objetivos da aprendizagem indicam. Desde a educação infantil até o ensino médio, essa concepção de Educação Física como linguagem é evidenciada e norteia todo o documento da Base e, a partir desse entendimento, os objetivos do ensino da educação física visam: a) compreender a origem e dinâmica das práticas sociais que constituem a cultura corporal de movimento; b) vivenciar e desfrutar das práticas corporais; c) bem como ser capaz de utilizar as práticas corporais no momento de lazer e cuidados com a saúde e reivindicar as condições necessárias para essas práticas. (GONTIJO, 2015; MARTINELLI et al, 2016; NEIRA E JÚNIOR, 2016; NEIRA, 2018).

Partindo da concepção de que não existe "a avaliação", mas um conjunto de possibilidades de avaliações, que sinalizam o caminhar dos alunos, dos professores, das instituições formativas, no seu processo de aprender, ensinar e formar (SANTOS E MAXIMIANO, 2013). Em outro tópico das entrevistas, o enfoque se voltou para as estratégias metodológicas que nossos entrevistados utilizaram para construir suas práticas avaliativas, nos princípios ou critérios que elas eram baseadas ou se eles utilizavam algum autor ou bibliografia como referência, etc. A seguir apresentamos o olhar dos professores P.1 e P.2 também sobre estes aspectos: 
Acho importante o professor considerar as experiências motoras de cada aluno, assim como, a realidade que a criança está inserida [...] Minha avaliação é baseada no envolvimento dos alunos durante as aulas, na observação de melhoras no comportamento motor e afetivo de cada aluno. Não é baseada em nenhum autor. (P.1)

Principalmente, a observação da evolução de cada aluno e da sua interação com os demais colegas, vendo a importância da educação física na formação do cidadão. Avalio baseada nos princípios do Esporte Educacional, que se baseia em João Batista Freire. (P.2)

Darido (2005) comenta que, ao avaliar as habilidades motoras e as capacidades físicas, é importante comparar o progresso do aluno consigo e não em relação aos demais. Além das habilidades e as capacidades físicas também é possível avaliar outros componentes como, por exemplo: a capacidade de coletar notícias, de produzir textos, de debater sobre temas de interesse de toda a comunidade, de articular e discutir conceitos da área da Educação Física que foram desenvolvidos anteriormente.

Freire (1989) considera importante o poder de análise do professor com relação à criança, emergindo uma possível dificuldade para a aplicabilidade dessa avaliação. O autor ainda evidencia a relevância da experiência docente com grupos de crianças como fundamental, para que ele possa aproveitar, ao máximo, a avaliação, observando os alunos em suas múltiplas dimensões. Porém, para que isso seja possível, é indispensável que conheça bem seus alunos.

Já o Coletivo de Autores (1992) enfatiza a importância que conceitos como: "finalidades, conteúdos e forma", possuem para a construção de proposta de avaliação crítica e emancipatória. Além disso, os autores salientam a importância de uma apreciação crítica da sociedade, as condutas sociais dos alunos, a busca de conflitos no processo ensino-aprendizagem e a orientação para a melhoria deste, a prerrogativa dos princípios da ludicidade e da criatividade, o embate entre sujeito e sociedade, e por fim, a crítica, a reinterpretação e a redefinição de normas, valores, regras e padrões. (COLETIVO DE AUTORES, 1992).

Resende (1995), aponta qualidades do emprego da observação, como estratégia metodológica das práticas avaliativas. Entre outros aspectos, a observação é uma estratégia propicia para reforçar a dimensão diagnóstica da avaliação. Pois, através da observação, o professor tem a possibilidade de fazer diferentes diagnósticos de cada uma das suas "turmas" e também de cada um de seus alunos, especificamente. Alguns fragmentos de nossas entrevistas assinalam que todos eles, em algum momento, se utilizam da observação para ajudar a construir suas práticas avaliativas. Como anúncio, por exemplo, o entrevistado 
P.4 afirma: "Minha avaliação é baseada em conversas com a turma avaliada e também na observação do processo educativo durante as aulas" (P.4)

Charlot (2000) trata das formas com que todo indivíduo constrói saberes, apropriando-se do mundo, de sua prática, de sua experiência. Portanto, o ato de aprender requer tempo e nunca está totalmente completo, jamais acaba. Assim, para Charlot a fomação é permanente, e isso é uma conquista que acompanha todo indivíduo.

Esse tempo é o de uma história: a da espécie humana, que transmite um patrimônio a cada geração. Esse tempo que não é homogêneo é ritmado por "momentos" significativos, por ocasiões, por rupturas; é o tempo da aventura humana, a da espécie, a do indivíduo. Esse tempo, por fim, se desenvolve em três dimensões, que se interpenetram e se supõem uma à outra: o presente, o passado, o futuro (CHARLOT, 2000. p. 79).

Ao enfocarmos no eixo da formação, problematizamos, com nossos depoentes, como eles compreendem a suas respectivas formações e às possíveis interferências dessa formação, na construção de suas práticas avaliativas. Vejamos algumas ideias sobre essa conexão, formação - prática avaliativa.

Sim, praticamente em todas as disciplinas da graduação tivemos pelo menos algum debate a respeito do processo avaliativo. Quanto a me espelhar em alguém ou em alguma experiência vivida, creio que sim, no início da minha carreira, mas hoje me baseio muito no que desenvolvi ao longo da caminhada, na convivência com os alunos. (P.4).

O depoimento do professor P.4 referenda alguns princípios pedagógicos elucidados pela pedagogia de Paulo Freire, como é o caso por exemplo do princípio de que "ninguém nasce educador ou marcado para ser educador. A gente se faz educador, a gente se forma, como educador, permanentemente na prática e na reflexão da prática" (FREIRE, 1991, p. 58).

Outro professor entrevistado reforçou a importância da formação continuada ou permanente. Ele destacou que: "na Universidade este tema foi dado de maneira superficial. Mas, com a Formação continuada da Rede de Parceiros Multiplicadores de Esporte Educacional, tive a prática e a experiência de uma avaliação justa” (P.2).

Garcia (1999 citado por SILVEIRA et al., 2007) observa que o desenvolvimento profissional é um processo constituído de estratégias de aperfeiçoamento imbuídos de reflexão sobre a sua própria prática. E acrescenta que a prática pedagógica produz conhecimento prático e estratégico que ajuda a constituir a identidade profissional.

$\mathrm{Na}$ entrevista do P.3, ele recorre as lembranças de aluno para, a partir delas, reconfigurar sua metodologia: 
Tive vários professores que apenas largavam a bola. Atitude que não adoto em minhas aulas. Procuro desenvolver os conteúdos dando ao aluno condições mínimas da prática desta ou daquela modalidade esportiva. (P.3)

Darido (2010) explica que é importante que o professor ultrapasse o vício que a Educação Física carrega consigo de apenas "jogar bola”, e salienta que, para um ensino de qualidade, é necessário o ampliar os conhecimentos. Dessa forma, se os alunos querem futebol, é importante que o professor consiga fazer com se amplie o conhecimento que já possuem dessa modalidade esportiva, de maneira que eles conheçam algumas relações que o futebol institui com a sociedade, etc. Ainda em relação ao trato metodológico dado aos esportes na Educação Física, Shigunov (1994) enfatiza que:

A partir da entrada na escola, os desportos poderão desempenhar um papel fundamental no desenvolvimento corporal e social da criança, desde que se relacionem com os fatores gerais da educação, numa exploração organizada e lúdica, direcionada para os objetivos multidisciplinares, característicos do processo ensino-aprendizagem atualmente proposto e visando ao desenvolvimento das potencialidades, bem como a integração na vida em sociedade (SHIGUNOV, 1994, p. 89).

$\mathrm{Na}$ perspectiva dos objetivos da nossa pesquisa, outra temática tratada nas entrevistas referiu-se a trajetória profissional dos entrevistados, mais especificamente, sobre como as suas experiências profissionais ajudaram na construção de suas atuais práticas avaliativas. Bermudes (2010) lembra que o processo de construção da prática avaliativa dar-se-á partir da estruturação de critérios e de instrumentos avaliativos.

Entre os 4 professores que entrevistamos todos fizeram referência ao uso da observação como um instrumento metodológico importante para a construção de suas práticas avaliativas. Haydt (1997) salienta que a observação sistemática do aluno em aula é um elemento indispensável à organização dos conceitos e das determinações a respeito da avaliação do processo de ensino-aprendizagem. A autora aponta também que, quando a observação é feita de forma sistemática ela pode contribuir tanto para a avaliação do aluno bem como para uma possível auto-avaliação do professor, seja para o alcance dos objetivos, seja para análise de sua metodologia de trabalho. Vejamos, um exemplo narrado por um dos nossos entrevistados sobre o uso da observação para a avaliação:

"Nas aulas práticas levo tarefas a serem realizadas pelos alunos. Por exemplo: trabalhei voleibol o sistema $6 \mathrm{x} 0$ e faço eles jogarem dentro deste sistema observando o grau de entendimento e organização dos alunos dentro do jogo. Mas com relação a temas voltados a saúde, exercitação física, faço alguns trabalhos avaliativos baseados em textos que levo para as turmas." (P.3) 
Darido (2010) lembra que a utilização de provas pode ser um instrumento útil, quando desejamos avaliar algumas capacidades do aluno, porém, para outras, a prova provavelmente não é o instrumento mais indicado. A autora cita o exemplo em que o objetivo seja avaliar os conhecimentos em situações, que exigem argumentações e discussões com outras pessoas. Nesse caso, o modelo de prova individual tradicional não será o meio mais adequado para implementar a avaliação daquilo que se pretende avaliar. Um dos nossos entrevistados comentou sobre como, ao longo de sua trajetória profissional, ele foi fazendo opções por certos instrumentos avaliativos em detrimento de outros: "O primeiro critério que utilizei foi a prova discursiva, depois não usei mais este método. Hoje em dia utilizo a observação do crescimento dos alunos em relação ao conteúdo trabalhado.” (P.4)

Darido (2010) salienta que observar é direcionar cuidadosamente o olhar. Assim, aqueles professores que atendem muitas turmas, e turmas com muitos alunos, o uso da prática de um registro pode ajudar na observação. Pode-se, preparar o registro e verificar, em uma aula específica, em forma de observação, se, por exemplo, os alunos compreenderam a dinâmica do "jogo dos dez passes", quais são as linhas demarcatórias da quadra, bem como os momentos em que a bandeja deve ser utilizada. Esta estratégia metodológica de aliar a observação com a prática do registro mencionada pelos nossos quatro entrevistados, um deles a especificou dizendo: "como atuo nos anos iniciais, faço observações e anotações a cada aula. Analiso as dificuldades de cada aluno e seu desenvolvimento durante as aulas." (P.1)

Neste sentido, Greenvile e Fernandes (2007) esclarecem que a participação nas aulas e nas atividades propostas pelo professor deve ter o mesmo objetivo que têm nas demais disciplinas do currículo escolar, tais como: matemática, línguas, geografia, história, etc. Aliás, para a Educação Física, provavelmente a participação tenha uma relevância maior ainda, pois, apesar de se aprender para participar, nela, envolver-se para aprender pode ser mais pertinente do que em outras disciplinas.

Por fim, outra temática que tratamos nas entrevistas foi sobre o retorno da avaliação aos alunos. Nesse ponto, todos os 4 professores entrevistados disseram considerar fundamental o retorno da avaliação para os alunos.

Sim, acho importante este retorno. Porque é neste momento que o aluno fica sabendo do quanto cresceu dentro de uma prática, ou entendimento sobre determinado tema desenvolvido. O retorno da prática se dá pela própria prática, pois o aluno poderá exercê-la da melhor forma com interferência reduzida do professor. Já a respeito dos temas abordados de forma teórica, este retorno é dado 
ao aluno que este é questionado sobre o assunto e consegue expor seu conhecimento sobe o assunto (P.3)

Darido (2010) lembra que a responsabilidade da avaliação cabe ao professor, ao aluno e à equipe pedagógica. A autora ressalva que isso implica em tomada de decisões conjuntas, em que cada qual assuma a sua responsabilidade no processo avaliativo e, também, na definição dos objetivos da avaliação. Essa participação é importante para decidir se há ou não necessidades de mudar os rumos das práticas avaliativas utilizadas. Pois, bem observou Luckesi (1997), o desafio da educação e do processo pedagógico não está em avaliar, mas em conseguir implementar um ensino efetivo, que acolha o aluno e promova a inclusão, sem castigo ou punição.

\section{CONSIDERAÇÕES FINAIS}

O processo avaliativo é um ato complexo e pode se materializar através de diferentes procedimentos e estratégias metodológicas. Nossa pesquisa referendou estas premissas também para a área da Educação Física Escolar. Conclui-se que as práticas avaliativas mais utilizadas pelos professores foram: a observação do aluno em aula e a aplicação de provas e trabalhos teóricos. Também verificou-se que os professores se utilizaram da formação continuada e de saberes oriundos de suas experiências docentes para aperfeiçoar e qualificar suas práticas avaliativas.

Procede salientar que o suporte empírico que utilizamos, nessa pesquisa, ateve-se às entrevistas, em decorrência disso e da não utilização de outros suportes empíricos. Como por exemplo, a observação das práticas avaliativas dos professores entrevistados, nossa pesquisa se ateve aos discursos dos professores, sem adentrarmos na análise da coerência ou não desses discursos. Assim, consideramos que demais pesquisas, que tenham como referência outras fontes empíricas, provavelmente irão trazer conclusões referentes à avaliação na Educação Física Escolar, diferentes e complementares àquelas assinaladas por essa pesquisa.

Por fim, consideramos importante ressaltar que a avaliação é um componente de um processo educativo. Portanto, muito mais do que um ponto de chegada, ela é um ponto mediador do processo de ensino e aprendizagem. Assim, mais do que um instrumento classificatório, essas práticas deveriam ser concebidas como recursos metodológicos construídos para qualificar a prática pedagógica, o processo de ensino, a aprendizagem e o trabalho docente. 


\section{REFERÊNCIAS}

BARDIN, L. Análise de conteúdo. Lisboa: Edições 70, 1990.

BERMUDES, R. Construção dos Saberes Sobre as Práticas Avaliativas dos Professores de Educação Física. 2010. Dissertação (Mestrado em Ciências) - Escola Superior de Educação Física, Universidade Federal de Pelotas, Pelotas/RS.

BRASIL. Lei $\mathrm{n}^{\circ}$. 9.394, de 20 de dezembro de 1996. Estabelece as Diretrizes e Bases da Educação Nacional. Legislação, Brasília/DF, dez. 1996. Disponível em: <http://portal.mec.gov.br/ arquivos/pdf/ldb.pdf>. Acesso em: 24 de abril, 2016.

BRASIL. Base Nacional Comum Curricular. Legislação, Brasilia/DF, dezembro de 2017. Disponível em: <http://basenacionalcomum.mec.gov.br/images/BNCC_EI_EF_110518_versao final_site.pdf> Acesso em 13 de junho de 2019.

CHARLOT, B. Da relação com o saber: elementos para uma teoria. Porto Alegre: Artes Médicas Sul, 2000.

COLETIVO DE AUTORES. Metodologia do Ensino de Educação Física. São Paulo: Cortez, 1992.

DARIDO, S. C. JUNIOR, O. M. S. Para ensinar Educação Física: Possibilidades de Intervenção na Escola. 6 $6^{\text {a }}$ ed. Campinas: Editora Papirus, 2010.

DARIDO. C. S. RANGEL, A. C. I. Educação Física na Escola. Rio de Janeiro: Guanabara Koogan, 2005.

FREIRE, M. A Formação Permanente. In: FREIRE, P. (Org.): Trabalho, Comentário, Reflexão. Petrópolis: Vozes, 1991.

FREIRE, J. B. Educação de Corpo Inteiro: Teoria e Prática da Educação Física. São Paulo: Scipione, 1989.

FEITOSA, W. M. N. NASCIMENTO, J. V. Educação Física: quais competências? In: SOUZA NETO, S. E HUNGER, D. (Orgs.) Formação Profissional em Educação Física. Rio Claro: Biblioteca, 2006.

FERREIRA, A.B.H. Novo dicionário da Língua Portuguesa, 2a ed. São Paulo: Nova Fronteira, 1986.

FERNANDES, S. GREENVILE, R. Avaliação da Aprendizagem na Educação Física Escolar. Motrivivência, ano XIX, nº 28, p. 120-138 Jul/2007.

GIL, A. C. Métodos e técnicas de pesquisa em ciências sociais. $5^{\text {a }}$ ed. São Paulo: Atlas, 1999.

GIL, A. C. Métodos e Técnicas de Pesquisa Social. $5^{\text {a }}$ ed. São Paulo: Atlas, 2007.

GONTIJO, C.M.M. Base Nacional Comum Curricular (BNCC): comentários críticos. Revista Brasileira de Alfabetização, v. 1, no 2, p. 174-190, jul./dez. 2015

HAYDT, R. C. Avaliação do Processo Ensino-Aprendizagem. 6a ed. São Paulo: Ática, 1997.

LAKATOS, E. M. MARCONI, M. A. Fundamentos de Metodologia Científica. São Paulo. Atlas, 1985.

LIBÂNEO, J.C. Didática. São Paulo: Cortez, 1994.

LUCKESI, C. C. Avaliação da Aprendizagem Escolar, 6ª ed. São Paulo: Cortez, 1997.

MARTINELI, T. A. P. MAGALHÃES, C. H. MILESKI, K. G. ALMEIDA, C. M. A educação física na BNCC: concepções e fundamentos políticos e pedagógicos. Motrivivência, v. $28, n^{\circ} 48$, setembro/2016.

MINAYO, M. C. S. (Org.). Pesquisa social: teoria, método e criatividade. Rio de Janeiro: Vozes, 2001. 
NEIRA, M.G. Incoerência e inconsistências da BNCC de Educação Física. Rev. Bras. Ciênc. RBCE Esporte. 2018. Disponível em: <https://doi.org/10.1016/j.rbce.2018.04.001〉. Acesso em: 13 de junho de 2019.

NEIRA, M.G. JÚNIOR, M. S. A educação física na BNCC: procedimentos, concepções e efeitos. Motrivivência, v. 28, n 48, p. 188-206, setembro/2016.

RAMALHO, B. L. NUÑEZ, I. B. GAUTHIER, C. Formar o professor, profissionalizar o ensino: perspectivas e desafios. Porto Alegre: $2^{\mathrm{a}}$ ed. Sulina, 2004.

RESENDE, H. G. Necessidades da Educação Motora na Escola. Pensando a Educação Motora. Campinas: Papirus, 1995. p. 71-91. (Coleção Corpo e Motricidade).

SANTOS, W. MAXIMIANO, F. L. Memórias discentes em Educação Física na educação básica: práticas avaliativas. Porto Alegre: Revista Movimento, v. 19, n. 02, p. 79-101, abr/jun de 2013.

SMOLE, K. C. S. Avaliação Escolar. São Paulo: Portal Salesianos, 2010. Disponível em: <http://www.salesianos.com.br/downloads/SubsidioRSE6.pdf>. Acesso em: 05 de maio de 2016.

SILVEIRA, J. S. BASEI, A. P. MASCHIO, V. SILVA, M. S. KRUG, H. N. As Ações pedagógicas dos Professores de Educação Física no desenvolvimento profissional. Disponível em: <www.sieduca.com.br/2007/index2411.html>. Acesso em: 18 de maio de 2016.

SHIGUNOV, V. Estudo das habilidades de ensino: estudos comparativos entre a teoria e a realidade. Paraná: Revista Unimar, v. 15 nº 2, p. 173-188, 1994.

TARDIF, M. E RAYMOND, D. Saberes, tempo e aprendizagem do trabalho no magistério. In: Educação \& Sociedade, ano XXI, n 73, dez. 2000.

TRIVIÑOS, A. N. Introdução à Pesquisa em Ciências Sociais: A Pesquisa Qualitativa em Educação. São Paulo: Editora Atlas, 1987.

\author{
EDITORA E GRÁFICA DA FURG \\ CAMPUS CARREIROS \\ CEP 96203900 \\ editora@furg.br
}

